\title{
DeterminaÇão Experimental da Entalpia de Vaporização da Água: Uma Actividade EXPerimental AdeQuAda à Disciplina de Física e Química A - Nível 1
}

\author{
Mário Valente \\ Colégio D. Duarte, Rua Visconde de Setúbal, 86, Porto \\ madmage1@yahoo.com
}

\begin{abstract}
Nesta contribuição descreve-se uma actividade experimental de realização simples, por nós criada e desenvolvida, envolvendo material facilmente acessível em qualquer laboratório escolar, que consiste na determinação da entalpia de vaporização da água, à pressão ambiente. Envolvendo materiais de aquisição fácil e económica, esta actividade enquadra-se perfeitamente no âmbito da disciplina de Física e Química A - nível 1.
\end{abstract}

\section{INTRODUÇÃOO}

Apesar da crescente tendência para a "virtualização" da componente prática do ensino das ciências em geral, e da Física e da Química em particular, consideramos que a "fuga” aos laboratórios, muitas vezes tentativamente justificada das mais diversas formas (por exemplo falta de equipamento e/ou reagentes, falta de tempo, falta de informação), traz consequências muito graves no que concerne à cultura científica das gerações de alunos que neste momento frequentam o ensino secundário, e que se já se reflectem no número de candidatos aos cursos superiores nestas áreas.

Acreditamos que a realização de actividades experimentais, além das constantes nos programas das disciplinas envolvendo Física e Química, promovem a aquisição de prática laboratorial e estimulam a formação de espíritos simultaneamente científicos e experimentalistas, essenciais à aquisição de competências e, em última análise, ao gosto por estas áreas basilares da Ciência. Salientamos que a actividade proposta de seguida se enquadra perfeitamente no âmbito do primeiro ano da disciplina bianual de Física e Química A, do ensino secundário [1].

A determinação experimental de grandezas de valores conhecidos é sempre um desafio interessante para os alunos já que permite a comparação com valores tabelados, passando o trabalho a assumir, além do mais, uma dimensão de desafio: "será que conseguimos chegar ao valor correcto?”. Assim, propõe-se, neste artigo, a determinação experimental da entalpia de vaporização da água (à pressão ambiente) por um método simples e de resultados razoavelmente exactos quando comparados com o valor conhecido.

\section{Prática de Laboratório}

Esta actividade requer a utilização de garrafas termos (de paredes duplas), de aquisição fácil e barata no comércio (por exemplo lojas de artigos orientais), e de termómetros digitais com uma precisão mínima de $0,1^{\circ} \mathrm{C}$, correntemente utilizados em muitos trabalhos de realização obrigatória, em várias disciplinas do ensino secundário.
Inicialmente procede-se ao aquecimento, até à ebulição, de uma dada massa de água (cerca de $500 \mathrm{~mL}$ ), e à medição da massa da garrafa termos vazia $\left(m_{0}\right)$. De seguida coloca-se alguma da água fervente na garrafa termos, até cerca de $5 \mathrm{~cm}$ do gargalo, tendo o cuidado de não deixar cair água nas paredes exteriores do recipiente. Agita-se cuidadosamente(!) a garrafa termos durante cerca de $10 \mathrm{~s}$ de modo a permitir que a temperatura das paredes interiores do recipiente (e da água nele contida) estabilize. Mede-se então a massa da garrafa termos cheia com água (massa inicial, $m_{i}$ ) e a temperatura da água (temperatura inicial, $\Theta_{i}$ ). Então, com uma "palhinha”, ou um tubo de borracha, sopra-se gentilmente, durante cerca de 20 s, para a superfície livre da água contida na garrafa termos para favorecer a vaporização de alguma água, tendo o cuidado de impedir que a palhinha (ou o tubo) toque quer na água aí contida, quer nas paredes do recipiente. Findo este tempo, determina-se a massa da garrafa termos (massa final, $m_{f}$ ) e a correspondente temperatura da água (temperatura final, $\Theta_{f}$ ).

A massa de água restante no interior da garrafa termos (não vaporizada), calculada segundo:

$$
m_{a}=m_{f}-m_{0}
$$

cedeu o calor necessário à vaporização $\left(Q_{\text {vap }}\right)$ da massa de água vaporizada $\left(m_{v}\right)$, que é igual à diferença de massas entre a garrafa termos cheia inicial e cheia final, calculada segundo:

$$
m_{v}=m_{i}-m_{f}
$$

Admitindo que a capacidade térmica mássica da água é constante no intervalo de temperaturas considerado (e igual a $4186 \mathrm{~J} /\left(\mathrm{kg} \cdot{ }^{\circ} \mathrm{C}\right)$ ), pode-se calcular o calor envolvido no processo de vaporização, segundo:

$$
Q_{\text {vap }}=4186 \times m_{a} \times\left(\Theta_{f}-\Theta_{i}\right) \text {. }
$$

O cálculo da entalpia de vaporização da água pode então ser feito segundo:

$$
\Delta H_{\text {vap }}=-Q_{\text {vap }} \div m_{v} \text {. }
$$


O sinal negativo presente na equação 4 é devido ao facto da massa de água que vaporizou ter absorvido o calor calculado segundo a equação 3 .

Para efeitos de comparação citam-se os resultados de uma experiência típica efectuada no nosso laboratório:

$m_{v}=0,28390 \mathrm{~kg} ; m_{i}=0,50256 \mathrm{~kg} ; m_{f}=0,50034 \mathrm{~kg} ;$

$\Theta_{i}==87,8^{\circ} \mathrm{C} ; \Theta_{f}=82,3^{\circ} \mathrm{C}$.

Assim, segundo a equação 2:

$$
\begin{aligned}
& m_{v}=m_{i}-m_{f} \\
& m_{v}=0,50256 \mathrm{~kg}-0,50034 \mathrm{~kg}=0,00222 \mathrm{~kg}
\end{aligned}
$$

segundo a equação 1:

$$
\begin{aligned}
& m_{a}=m_{f}-m_{0} \\
& m_{a}=0,50034 \mathrm{~kg}-0,28390 \mathrm{~kg}=0,21644 \mathrm{~kg}
\end{aligned}
$$

segundo a equação 3:

$$
\begin{aligned}
& Q_{\text {vap }}=4186 \times m_{a} \times\left(\Theta_{f}-\Theta_{i}\right) \\
& Q_{\text {vap }}=\left[4186 \mathrm{~J} /\left(\mathrm{kg} \cdot{ }^{\circ} \mathrm{C}\right)\right] \times 0,21644 \mathrm{~kg} \times\left(82,3^{\circ} \mathrm{C}-87,8^{\circ} \mathrm{C}\right)= \\
& =-4,98 \cdot 10^{3} \mathrm{~J}
\end{aligned}
$$

e segundo a equação 4:

$$
\begin{aligned}
& \Delta H_{\text {vap }}=-Q_{\text {vap }} \div m_{v} \\
& \Delta H_{\text {vap }}=4,98 \cdot 10^{3} \mathrm{~J} \div 0,00222 \mathrm{~kg}=2,24 \cdot 10^{6} \mathrm{~J} / \mathrm{kg}
\end{aligned}
$$

\section{AnÁlise e crítica dos Resultados}

Numa aula em que vários grupos realizem o trabalho, e para efectuar a análise dos dados, aconselha-se o cálculo da média dos resultados, do correspondente desvio médio $(d m)$ e do erro relativo $(E R)$ associado à determinação experimental $\left(X_{e}\right)$, relativamente ao valor tabelado $\left(X_{t}\right)$ que é $2,26 \cdot 10^{6} \mathrm{~J} / \mathrm{kg}[2]$.

O desvio médio associado a uma série de $\boldsymbol{n}$ experiências é determinado segundo:

$$
d m=\frac{\sum_{i=1}^{n}\left|X_{e}-X_{i}\right|}{n}
$$

O erro relativo é determinado segundo:

$$
E R=\frac{\left|X_{t}-X_{e}\right|}{X_{t}} \times 100
$$

e considerando os dados do exemplo apresentado, tem-se:

$E R=\left(2,26 \cdot 10^{6}-2,24 \cdot 10^{6}\right) \times 100 \div 2,26 \cdot 10^{6}=0,885 \%$

Deve salientar-se aos alunos que os resultados experimentais são afectados de erros devido a uma série de razões que, neste caso específico, entre outras, incluem:

- remoção de água por contacto com a palhinha (ou tubo);

- remoção de água por projecção devido a soprar com demasiado vigor;

- remoção de calor por introdução do termómetro na água, na segunda medição;

- para um conjunto de experiências realizadas no nosso laboratório obtivemos o resultado: 2,3( $\pm 0,1) \cdot 10^{6} \mathrm{~J} / \mathrm{kg}$ $(E R=3,5 \%)$.

\section{Conclusão}

A actividade experimental sugerida neste artigo constitui um exemplo de um trabalho experimentalmente bastante acessível, didáctica e pedagogicamente enriquecedor, que permite aos alunos um contacto prático com uma técnica calorimétrica básica, enquanto observam o fenómeno estudado (vaporização da água). É importante notar que os resultados experimentais obtidos são bastante próximos do valor tabelado. O maior cuidado a ter durante a execução laboratorial resume-se a evitar queimaduras térmicas devido a contacto com água a elevada temperatura.

\section{BIBLIOGRAFIA}

[1] Programa da disciplina de Física e Química A (níveis 1 e 2) $10 .^{\circ}$ ou $11 .^{\circ}$ anos: http://www.dgidc.min-edu.pt/ensinosecundario/ (Ministério da Educação e Ciência, acedido em 9-1-2014).

[2] http://en.wikipedia.org/wiki/Enthalpy_of_vaporization (acedido em 9-1-2014).
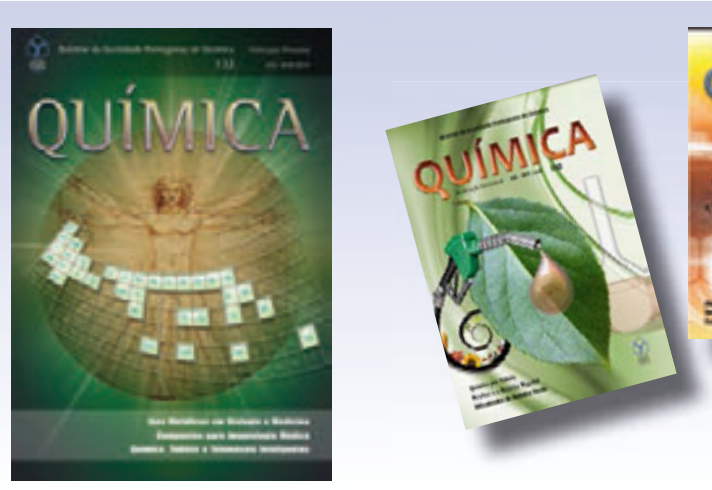

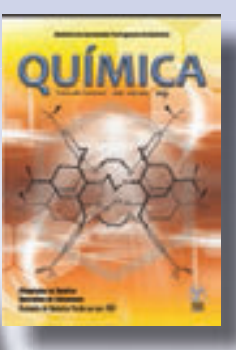

Publique no boletim QUÍMICA

(bquimica@quimica.uminho.pt) 